\title{
PROPRIEDADES BIOLÓGICAS EM AGREGADOS DE UM LATOSSOLO VERMELHO-ESCURO SOB PLANTIO CONVENCIONAL E DIRETO NO CERRADO(1)
}

\author{
I. C. MENDES ${ }^{(2)}$, L. V. SOUZA(3), D. V.S. RESCK(4) \& A. C. $\operatorname{GOMES}^{(4)}$
}

\begin{abstract}
RESUMO
As distribuições do carbono da biomassa microbiana (CBM), da atividade enzimática e do C mineralizável foram avaliadas em agregados, coletados na profundidade de 0-0,05 m, de um Latossolo Vermelho-E scuro argiloso, sob vegetação nativa de Cerrado e sob sistemas de plantio direto (PD) e convencional com arado de discos (PC), estabelecidos há 21 anos. A separação dos agregados foi realizada por via úmida. As classes de 8,00-2,00 mm; 0,50-0,25 mm e 0,25$0,106 \mathrm{~mm}$ e amostras denominadas soma de agregados foram selecionadas para as determinações biológicas. Em relação à área nativa, os sistemas cultivados causaram quebra de macroagregados e perda de CBM. A aplicação localizada de adubos, o menor revolvimento do solo e os mai ores teores de matéria orgânica no PD favoreceram, em relação ao PC, a ocorrência de maiores níveis de fosfatase ácida e arilsulfatase nos agregados e nas amostras que representavam a soma de agregados. Os microagregados e a soma dos agregados do PD também apresentaram maiores teores de CBM, comparativamente ao PC. As maiores atividades da $\beta$-glucosidase foram observadas nos macro e microagregados do PD. Os sistemas de manejo (PD e PC) influenciaram a distribuição das propriedades biológicas nos agregados. A atividade das enzimas $\beta$-glucosidase, fosfatase ácida e arilsulfatase foi maior em macroagregados do PD apesar da distribuição semelhante do CBM nas três classes de agregados avaliadas. No PC, apenas $\beta$-glucosidase apresentou distribuição diferenciada entre macro e microagregados.
\end{abstract}

Termos de Indexação: biomassa microbiana, carbono mineralizável, enzimas do solo, fosfatase ácida, $\beta$-glucosidase, arilsulfatase.

(1) Recebido para publicação em agosto de 2002 e aprovado em março de 2003.

(2) Pesquisadora da Embrapa Cerrados. Caixa Postal 08223, CEP 73301-970 Brasília (DF). E-mail: mendesi@cpac.embrapa.br

(3) Engenheira-Agrônoma, Universidade de Brasília - FAV/UNB. Campus Darci RibeirolCC Ala Sul. CEP $70910-970$ Brasília (DF).

(4) Pesquisador da Embrapa Cerrados. Caixa Postal 08223, CEP 73301-970 Brasília (DF). E-mail: dvsresck@cpac.embrapa.br; acgomes@cpac.embrapa.br 


\title{
SUMMARY: BIOLOGICAL PROPERTIES OF AGGREGATES FROM A CERRADO OXISOL UNDER CONVENTIONAL AND NO-TILL MANAGEMENT SYSTEMS
}

\begin{abstract}
The distributions of microbial bi omass carbon (MBC), enzymes activities and readily mineralizablecarbon wereevaluated across soil aggregates recovered from a Dark-Red Clayey Oxisol in areas under nativeCerrado vegetation and whereno-tillage(NT) and conventional tillage (CT) management systems have been established for 21 years. Soil samples were collected at a 0 to $5 \mathrm{~cm}$ depth and aggregates wereprepared using a wet si eving procedure. The size classes 8.0 to $2.0 \mathrm{~mm}, 0.5$ to $0.25 \mathrm{~mm}$ and 0.25 to $0.106 \mathrm{~mm}$ and samples denomi nated sum of aggregates (SA) weresel ected for biological determinations. In relation to the native Cerrado the agricul tural systems caused the disruption of macroaggregates and Iosses of MBC. As compared to the CT, the reduced soil tillage, the accumulation of organic matter and the localized application of fertilizers in the NT system favored higher levels of acid phosphatase and arylsulfatase in its aggregates and SA samples. NT microaggregates and SA samples presented higher levels of MBC as compared do the CT. Thehighest activities of $\beta$-glucosidasewereal so found in theNT macro and mi croaggregates. TheNT and CT management systems influenced thedistribution profile, in soil aggregates, of the biological properties evaluated. Acid phosphatase, $\beta$-glucosidase and arylsulfatase activities werehigher in theNT macroaggregates, in spite of theevenly distribution of MBC in the three aggregate size classes evaluated. In the CT, only $\beta$-gl ucosidase presented an uneven distribution in macro and microaggregates.
\end{abstract}

Index terms: microbial biomass, readily mineralizableC, soil enzymes, acid phosphatase, $\beta$-glucosi dase, arylsulfatase

\section{INTRODUÇÃO}

Os agregados do sol o são compostos de partículas primárias (argila, silte e areia) e matéria orgânica que se aderem umas às outras (Kemper \& Rosenneau, 1986). A presença de agregados estáveis potencializa a capacidade de armazenamento de água, diminui as perdas de partículas e nutrientes por processos erosivos e facilita a proteção física e o acúmulo da matéria orgânica no solo (Miller \& J astrow, 1992; Foster, 1994). Além disso, os agregados constituem micro-habitats onde os microrganismos do solo encontram nutrientes e ficam protegidos contra a predação e dessecação.

De acordo com Tisdall \& Oades (1979), a formação e a estabilização de macro $(>0,25 \mathrm{~mm})$ e microagregados $(<0,25 \mathrm{~mm})$ dependem de fatores abióticos (presença de cátions cimentantes, processos físicos relacionados com umedecimento/secagem, congelamento/descongel amento e compactação) e bióticos (manejo de solo, partici pação mecânica das raízes de plantas e hifas fúngicas, presença de polissacarídeos, substâncias mucilaginosas e húmicas produzidas pelos organismos do solo).

O uso de implementos agrícolas no preparo do solo provoca alterações na distribuição e na estabilidade dos agregados, diminuindo a percentagem de macroagregados e aumentando a dos microagregados (Machado et al., 1981; Elliott,
1986; Gupta \& Germida, 1988; Coleman et al., 1994; Singh \& Singh, 1995; Castro Filho et al., 2002). A quebra dos macroagregados expõe a matéria orgânica armazenada no seu interior ao ataque dos microrganismos, promovendo sua perda (Elliott, 1986; Gupta \& Germida, 1988; Pereira et al., 1996).

A maior parte dos estudos relacionados com a agregação do solo concentra-se nas mudanças de estabilidade e de distribuição de tamanho de agregados que ocorrem após o estabelecimento de diferentes sistemas de manejo, os quais têm implicações na acumulação e, ou, na perda de matéria orgânica do solo (Dormaar, 1983; J astrow, 1987; 1996; Carpenedo \& Mielniczuk,1990; Buyanovsky et al., 1994; Albuquerque et al., 1995; Pereira et al., 1996; Six et al., 2000). Além de poucos, os trabalhos na literatura sobre a distribuição espacial de microrganismos nas diferentes classes de agregados do solo são concentrados nas regiões temperadas (Gupta \& Germida, 1988; Seech \& Beauchamp, 1988; Miller \& Dick, 1995a,b; Mendes et al., 1999a). N as regiões tropicais, especialmente no Cerrado, existem poucas informações sobre as propriedades biológicas de agregados do sol o e sobre o impacto de diferentes sistemas de manejo. Assim, o objetivo deste estudo foi avaliar a distribuição da biomassa microbiana, da atividade enzimática e do C mineralizável, em macro e em microagregados, col etados na profundidade 0 a $5 \mathrm{~cm}$, de um Latossolo Vermelho-Escuro argiloso, sob vegetação nativa 
(Cerrado) e sob sistemas de plantio direto (PD) e de plantio convencional com arado de discos (PC), estabel ecidos há 21 anos.

\section{MATERIAL E MÉTODOS}

\section{Caracterização da área}

O estudo foi realizado num experimento iniciado em 1979, na Embrapa Cerrados, Planaltina (DF), em um L atossolo Vermel ho-Escuro argil oso $\left(15^{\circ} 35^{\prime}\right.$ 30 "S e $\left.47^{\circ} 42^{\prime \prime} 00^{\prime} \mathrm{W}\right)$. O clima da região édo tipo tropical estacional (Aw), com precipitação média anual de $1.500 \mathrm{~mm}$ concentrada no período que vai de outubro a março. As médias das temperaturas máximas e mínimas são de 26,4 e $15,9{ }^{\circ} \mathrm{C}$, respectivamente.

Os tratamentos consistiram em faixas sob dois sistemas de manejo: plantio direto (PD), sem cultura de cobertura no inverno, e plantio convencional (PC). Uma área adjacente com vegetação nativa do tipo Cerrado sentido restrito foi incluída no estudo e utilizada, como referencial, para as condições originais do solo. No tratamento sob PC, antes do plantio, o solo foi preparado com arado de discos e grade niveladora (duas passagens) e, após a col heita, os resíduos vegetais foram incorporados ao sol o com 0 arado de disco, sem a gradagem.

As faixas dePD edePC mediam $25 \times 50 \mathrm{~m}$. Aolongo de uma diagonal, foram definidos aleatoriamente três pontos deamostragem eqüidistantes. Em cada ponto, foram coletadas 20 subamostras de solo que foram homogeneizadas earmazenadas, à temperatura de $7^{\circ} \mathrm{C}$, até o momento do penei ramento e realização dos ensaios.

A coleta de solo foi realizada no início da época chuvosa, 31 de outubro de 2000, na profundidade de 0 a $5 \mathrm{~cm}$. Optou-se por essa profundidade de amostragem porque, em alguns trabalhos na literatura (Beare et al., 1994; Six et al., 2000), foi verificado queas diferenças entre os sistemas dePD e de PC, com respeito à distribuição de agregados e à distribuição de $C$ nesses agregados, eram mais acentuadas nos $5 \mathrm{~cm}$ iniciais do solo.

\section{Separação dos agregados}

A separação dos agregados foi realizada por via úmida, utilizando um aparel ho Y oder, de oscilação vertical, graduado para uma amplitude de $40 \mathrm{~cm}$ de altura euma freqüência de 17 oscilações por minuto. Esse aparel ho contém jogos de peneiras com cinco malhas de diferentes diâmetros $(2,00,1,00,0,500$, 0,250 e 0,106 mm).

As amostras de solo foram pré-secas até atingirem um estado friável e passadas em uma peneira de $8,00 \mathrm{~mm}$ de diâmetro. Porções de $100 \mathrm{~g}$ dessas amostras foram colocadas sobre a malha da peneira superior $(2,00 \mathrm{~mm})$ dos jogos de peneiras do equipamento Yoder. Ajustou-se o nível de água dentro dos cilindros onde os jogos de peneiras estavam imersos, até que a malha do fundo da peneira superior tivesse uma fina lâmina de água para umedecer a amostra por capilaridade. As amostras de solo foram submetidas à agitação vertical por $30 \mathrm{~min}$. Após esse procedimento, os agregados retidos nas peneiras foram colocados em recipientes abertos, secos ao ar earmazenados a uma temperatura de $7 \stackrel{\circ}{\circ}$ por um período de 20 dias. Antes da realização das análises microbiológicas e bioquímicas, resíduos de plantas eraízes, presentes nas amostras, foram removidos cuidadosamente.

Para representar as amostras de solototal vindas do campo e submeti das ao penei ramento úmido, fezse uma composi ção a partir da mistura dos agregados retidos nas peneiras de 2,00, 1,00, 0,50, 0,25 e $0,106 \mathrm{~mm}$, após a separação por via úmida de subamostras de $100 \mathrm{~g}$ de solo. Essa amostra foi denominada soma dos agregados (SA), pois, embora represente o solo total, não inclui os agregados menores que 0,106 mm, que são perdidos no processo de peneiramento. Para as determinações microbiológicas e bioquímicas, foram selecionadas as classes 8,00-2,00; 0,50-0,25 e 0,25-0,106 mm. Adotando a área sob vegetação de Cerrado nativo como referencial, verificou-se, após o peneiramento úmido, que essas classes foram as que sofreram alterações mais expressivas em suas distribuições, principal mente na faixa sob PC, razão por que elas foram selecionadas para os estudos.

No quadro 1, são apresentadas as propriedades químicas das amostras de sol o total e das classes de agregados (EMBRAPA, 1997). Os teores de matéria orgânica dessas amostras foram determinados pelo método de Walkley \& Black (Nelson \& Sommers, 1982).

\section{Análises microbiológicas e bioquímicas}

\section{Carbono da biomassa microbiana (CBM)}

Utilizou-se o método clorofórmio-fumigaçãoincubação(CFI), proposto por J enkinson \& Polwson (1976), em que a biomassa microbiana é estimada com base na diferença na produção de $\mathrm{CO}_{2}$ de amostras de solo fumigadas com clorofórmio ( $F)$ e nãofumigadas (NF). Os procedimentos são descritos em detal hes por Oliveira et al. (2001).

\section{Carbono prontamente mineralizável}

O carbono prontamentemineralizável do sol o foi estimado por meio da quantidade de $\mathrm{CO}_{2}$ liberado do sol o não fumigado durante o período de 17 dias de incubação, conformedescrito por Oliveira et al . (2001).

\section{Atividade enzi mática do solo}

Foram avaliadas as atividades de enzimas do solo associadas ao ciclo do carbono ( $\beta$-glucosidase), do fósforo (fosfatase ácida) e do enxofre (arilsulfatase), 
Quadro 1. Propriedades químicas das classes de agregados e das amostras de solo total obtidas na área sob vegetação nativa de Cerrado sentido restrito e nas áreas cultivadas durante 21 anos $^{(1)}$

\begin{tabular}{|c|c|c|c|c|c|c|}
\hline \multirow{2}{*}{ Tratamento } & \multirow{2}{*}{ Classe de agregados } & \multicolumn{5}{|c|}{ Propriedade química } \\
\hline & & pH $\left(\mathrm{H}_{2} \mathrm{O}\right)$ & $\mathbf{H}+\mathbf{A l}$ & $\mathrm{Ca}+\mathrm{Mg}$ & $\mathbf{P}$ & $\mathbf{K}$ \\
\hline & $\mathrm{mm}$ & & $-\mathrm{mmo}$ & $\mathrm{dm}^{-3}-$ & $-\mathrm{m}$ & $\mathrm{m}^{-3}$ \\
\hline \multirow[t]{2}{*}{ Vegetação nativa } & $\begin{array}{l}8,00-2,00 \\
0,50-0,25 \\
0,25-0,106\end{array}$ & $\begin{array}{l}5,17 \\
5,37 \\
5,50\end{array}$ & $\begin{array}{r}94,6 \\
108,5 \\
81,8\end{array}$ & $\begin{array}{c}14,3 \\
9,90 \\
18,0\end{array}$ & $\begin{array}{l}3,00 \\
1,21 \\
1,09\end{array}$ & $\begin{array}{l}34,67 \\
23,67 \\
39,50\end{array}$ \\
\hline & Soma dos agregados & 5,53 & 107,3 & 10,0 & 0,81 & 24,33 \\
\hline \multirow[t]{2}{*}{ Plantio direto } & $\begin{array}{l}8,00-2,00 \\
0,50-0,25 \\
0,25-0,106\end{array}$ & $\begin{array}{l}5,30 \\
5,37 \\
5,57\end{array}$ & $\begin{array}{l}73,5 \\
66,9 \\
47,1\end{array}$ & $\begin{array}{l}53,4 \\
49,8 \\
44,7\end{array}$ & $\begin{array}{l}28,24 \\
28,78 \\
40,03\end{array}$ & $\begin{array}{r}110,33 \\
70,33 \\
52,00\end{array}$ \\
\hline & Soma dos agregados & 5,20 & 63,1 & 55,3 & 29,94 & 81,00 \\
\hline \multirow[t]{2}{*}{ Plantio convencional } & $\begin{array}{l}8,00-2,00 \\
0,50-0,25 \\
0,25-0,106\end{array}$ & $\begin{array}{l}5,43 \\
5,37 \\
5,63\end{array}$ & $\begin{array}{l}57,5 \\
50,4 \\
59,9\end{array}$ & $\begin{array}{l}31,0 \\
37,0 \\
39,2\end{array}$ & $\begin{array}{r}11,14 \\
8,00 \\
14,17\end{array}$ & $\begin{array}{l}63,67 \\
35,00 \\
44,00\end{array}$ \\
\hline & Soma dos agregados & 5,50 & 74,1 & 34,0 & 6,78 & 39,00 \\
\hline
\end{tabular}

(1) $\mathrm{Ca}$, Mg e Al foram extraídos com KCl $1 \mathrm{~mol} \mathrm{~L}^{-1}$ e determinados por meio de absorção atômica (Ca e Mg) e titulação com NaOH $0.025 \mathrm{~mol} \mathrm{~L}{ }^{-1}(\mathrm{Al})$. $\mathrm{K}$ e P foram extraídos pelo método M ehlich-1 $\left(\mathrm{H}_{2} \mathrm{SO}_{4} 0,0125 \mathrm{~mol} \mathrm{~L}^{-1}+\mathrm{HCl} 0,05 \mathrm{~mol} \mathrm{~L}^{-1}\right)$, e determinados por meio de espectrofotometria de chama e usando o método do Azul de Mo (EMBRAPA, 1997), respectivamente.

utilizando-se os métodos descritos por Tabatabai (1994). Esses métodos baseiam-sena determinação colorimétrica do p-nitrofenol (coloração amarela), formado após a adição de substratos incolores específicos a cada enzima avaliada. Para cada amostra de sol o col etada no campo, foram real izadas três repetições analíticas no laboratório.

\section{Análises estatísticas}

Para efetuar as comparações entre tratamentos e dentro das diferentes classes de agregados de um mesmo tratamento, foi utilizado o teste nãoparamétrico de Wilcoxon a $10 \%$.

\section{RESULTADOS E DISCUSSÃO}

\section{Distri buição dos agregados e matéria orgânica}

Com base nas amostras de solo coletadas na profundidade de 0 a $5 \mathrm{~cm}$, observou-se que, na área sob vegetação nativa, apenas $13 \%$ do solo era constituído por microagregados $(<0,25 \mathrm{~mm})$, enquanto, nas áreas sob PD ePC, essa percentagem foi de 20 e $24 \%$, respectivamente (Figura 1 ), representando aumentos de 54 e $85 \%$ nas quantidades de microagregados nessas áreas. $\mathrm{O}$ aumento acentuado na quantidade demicroagregados no solo sob PC é conseqüência da quebra dos macroagregados decorrente dos constantes cultivos mecânicos e das características operacionais do arado de discos. Esses cultivos diminuem a estabilidade dos macroagregados, tornando-os mais susceptíveis às forças de ruptura quando separados por via úmida. Resultados semel hantes, envolvendo áreas nativas e cultivadas, foram obtidos por Dormaar (1983); Elliot (1986); Gupta \& Germida (1988); Angers (1992) e Pereira et al. (1996).

$\mathrm{Na}$ área sob PC, na qual se utilizou arado de discos, a classe de macroagregados mais afetada foi a de 8,00-2,00 mm, que sofreu redução de $40 \%$ em relação à área nativa. $\mathrm{Na}$ área sob PD, essa redução foi de apenas $14 \%$, mostrando que, no PD, os macroagregados de $8,00-2,00 \mathrm{~mm}$ na profundidade

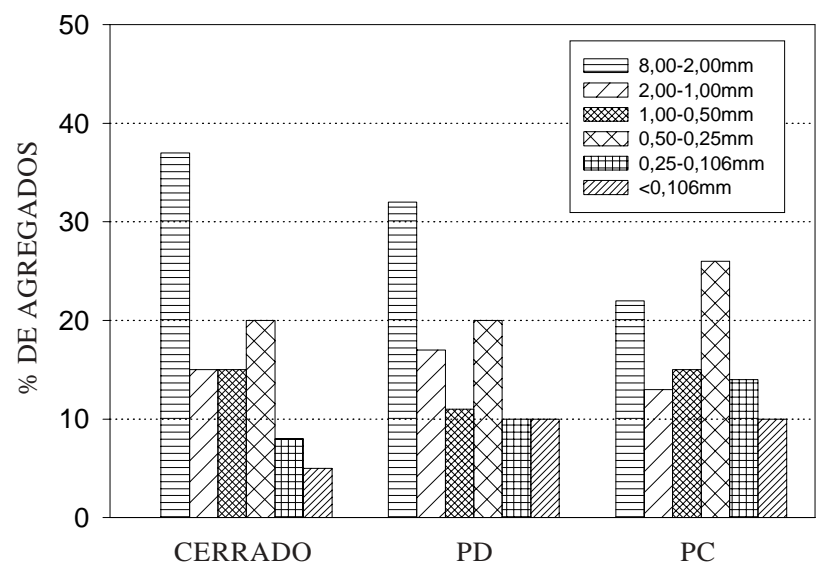

Figura 1. Distri buição do solo em diferentes classes de agregados nas áreas sob vegetação nativa, plantio direto (PD) e plantio convencional (PC). 
de 0 a 5 cm são mais estáveis que os do PC, conforme verificado por Carter (1992); Beare et al. (1994) e Six et al. (2000). Comoa estabilidade dos macroagregados está associada à presença de raízes e hifas fúngicas, sistemas de manejo como o PD, além de favorecer esses fatores eapresentar maiores teores de matéria orgânica, principalmente na profundidade de 0 a $5 \mathrm{~cm}$, tendem a aumentar a estabilidade dos macroagregados, quando comparados a sistemas de manejo que envolvem o revolvimento do solo, como oPC.

Os teores de matéria orgânica na soma de agregados e nos macroagregados da área sob vegetação nativa eda área sob PD foram semelhantes, mas significativamente superiores aos do PC (Quadro 2). Não houve diferenças entre os teores de matéria orgânica dos microagregados das três áreas.

Resck (1993) também observou que PD foi o sistema que mel hor protegeu a matéria orgânica do solo, pois funciona à semelhança de um ambiente não perturbado. Esse autor também verificou reduções acentuadas nos teores de matéria orgânica nas amostras de sol o total e nos macroagregados de áreas sob plantio convencional com grade pesada e enxada rotativa.
Na área sob vegetação nativa e no PD, os teores de matéria orgânica dos macroagregados foram significativamente superiores aos dos microagre gados, enquanto, no PC, os teores de matéria orgânica nos macro e microagregados foram semel hantes (Quadro 2). Conforme verificado por Gupta \& Germida (1988) eF ranzluebbers \& Arshad (1997), esses resultados evidenciam não só a capacidade de os macroagregados estáveis em água (como os do Cerrado e do PD) protegerem a matéria orgânica do ataque microbiano, mas também o fato de serem os efeitos do PC mais acentuados nos macroagregados.

\section{Carbono da biomassa microbiana, carbono prontamente mineralizável e atividade enzimática}

Observou-se que a soma de agregados e os agregados da área sob vegetação nativa apresentaram os maiores níveis de $\mathrm{C}$ da biomassa microbiana (CBM) (Quadro 2). O PC apresentou os menores níveis e o PD mostrou valores intermediários entre o Cerrado e o PC. As diferenças entre a área sob vegetação nativa e o PC foram estatisticamente significativas em todas as classes de agregados e na amostra soma de agregados; já as diferenças entre a área sob vegetação nativa e o PD foram

Quadro 2. Matéria orgânica e propriedades biológicas dos agregados e das amostras de solo total obtidas na área sob vegetação nativa de Cerrado sentido restrito e nas áreas cultivadas durante 21 anos

\begin{tabular}{|c|c|c|c|c|c|}
\hline & \multirow{2}{*}{ Tratamento } & \multicolumn{3}{|c|}{ Classe de agregado } & \multirow{2}{*}{ Soma dos agregados } \\
\hline & & $8,00-2,00 \mathrm{~mm}$ & $0,500-0,250 \mathrm{~mm}$ & $0,250-0,106 \mathrm{~mm}$ & \\
\hline Matéria orgânica(1) & $\begin{array}{l}\text { Vegetação nativa } \\
\text { Plantio direto } \\
\text { Plantio convencional }\end{array}$ & $\begin{array}{l}37,5 \text { aA } \\
34,1 \text { aA } \\
23,9 \mathrm{bA}\end{array}$ & $\begin{array}{l}35,3 \text { aA } \\
29,6 \text { aA } \\
21,3 \text { bA }\end{array}$ & $\begin{array}{l}25,5 \mathrm{aB} \\
22,2 \mathrm{aB} \\
21,4 \mathrm{aA}\end{array}$ & $\begin{array}{l}35,1 \mathrm{a} \\
32,7 \mathrm{a} \\
23,2 \mathrm{~b}\end{array}$ \\
\hline CBM(2) & $\begin{array}{l}\text { Vegetação nativa } \\
\text { Plantio direto } \\
\text { Plantio convencional }\end{array}$ & $\begin{array}{l}478 \text { aA } \\
238 \text { abA } \\
150 \mathrm{bA}\end{array}$ & $\begin{array}{r}510 \mathrm{aA} \\
172 \mathrm{bA} \\
84 \mathrm{bA}\end{array}$ & $\begin{array}{r}282 \mathrm{aB} \\
178 \mathrm{aA} \\
80 \mathrm{bA}\end{array}$ & $\begin{array}{l}433 a \\
209 b \\
122 c\end{array}$ \\
\hline C mineralizável(2) & $\begin{array}{l}\text { Vegetação nativa } \\
\text { Plantio direto } \\
\text { Plantio convencional }\end{array}$ & $\begin{array}{l}180 \text { aA } \\
153 \text { abA } \\
92 \text { b A }\end{array}$ & $\begin{array}{l}152 \mathrm{aAB} \\
149 \mathrm{aA} \\
90 \mathrm{aA}\end{array}$ & $\begin{array}{l}98 \mathrm{aB} \\
97 \mathrm{aA} \\
79 \mathrm{aA}\end{array}$ & $\begin{array}{l}174 a \\
127 a \\
124 a\end{array}$ \\
\hline$\beta$-Glucosidase ${ }^{(3)}$ & $\begin{array}{l}\text { Vegetação nativa } \\
\text { Plantio direto } \\
\text { Plantio convencional }\end{array}$ & $\begin{array}{l}41 \mathrm{bA} \\
70 \mathrm{aA} \\
47 \mathrm{bA}\end{array}$ & $\begin{array}{l}32 \mathrm{bB} \\
69 \mathrm{aA} \\
33 \mathrm{bB}\end{array}$ & $\begin{array}{l}23 \mathrm{bC} \\
39 \mathrm{aB} \\
24 \mathrm{bC}\end{array}$ & $\begin{array}{l}26 a \\
52 a \\
24 a\end{array}$ \\
\hline F osfatase ácida(3) & $\begin{array}{l}\text { Vegetação nativa } \\
\text { Plantio direto } \\
\text { Plantio convencional }\end{array}$ & $\begin{array}{l}797 \mathrm{aA} \\
471 \mathrm{aA} \\
243 \mathrm{bA}\end{array}$ & $\begin{array}{l}868 \text { aA } \\
479 \text { aA } \\
239 \mathrm{bA}\end{array}$ & $\begin{array}{l}580 \mathrm{aA} \\
348 \mathrm{aB} \\
200 \mathrm{bA}\end{array}$ & $\begin{array}{l}868 a \\
499 b \\
257 c\end{array}$ \\
\hline Arilsulfatase(3) & $\begin{array}{l}\text { Vegetação nativa } \\
\text { Plantio direto } \\
\text { Plantio convencional }\end{array}$ & $\begin{array}{l}68 \mathrm{aA} \\
50 \mathrm{aA} \\
16 \mathrm{bA}\end{array}$ & $\begin{array}{l}76 \mathrm{aA} \\
50 \mathrm{aA} \\
18 \mathrm{bA}\end{array}$ & $\begin{array}{l}51 \mathrm{aA} \\
30 \mathrm{aB} \\
11 \mathrm{bA}\end{array}$ & $\begin{array}{l}73 a \\
48 a \\
16 b\end{array}$ \\
\hline
\end{tabular}

(1) $\mathrm{g} \mathrm{kg}^{-1}$ de solo. ${ }^{(2)}$ Carbono da biomassa microbiana, $\mathrm{mg} \mathrm{kg}^{-1}$ de $\mathrm{C}$ no solo. ${ }^{(3)} \mu \mathrm{g}$ p-nitrofenol $\mathrm{g}^{-1} \mathrm{~h}^{-1}$ de solo. Letras minúsculas, dentro de uma mesma coluna, referem-se à comparação entre tratamentos para uma mesma classe de agregados. Letras maiúsculas, dentro de uma mesma linha, referem-se à comparação entre classes de agregados de um mesmo tratamento. Em ambos os casos, valores seguidos pelas mesmas letras não diferem entre si pelo teste de Wilcoxon $(p<0,10)$. 
significativas somente na classe de 0,500-0,250 mm ena soma de agregados. Gupta \& Germida (1988) e Singh \& Singh (1995) também observaram maiores quantidades de CBM em macroagregados de áreas nativas. Eles atribuíram esse fato à maior presença de hifas fúngicas e bactérias associadas a esses agregados. Resultados semel hantes, com amostras de solo (profundidade de 0 a $5 \mathrm{~cm}$ ) do bioma Cerrado, foram observados por Mendes et al . (1999b), Oliveira (2000) e Matsuoka (2001), que também verificaram reduções acentuadas nos níveis de CBM, após a incorporação de solos sob vegetação nativa aos processos agrícolas.

Os agregados do PD apresentaram mai ores níveis de CBM que os do PC, sendo essas diferenças estatisticamente significativas nos microagregados $(0,250-0,106 \mathrm{~mm})$ e na soma de agregados (Quadro 2). Esses resultados evidenciam que também no bioma Cerrado, semel hantemente ao observado em outras partes do mundo (Doran, 1980; Hernández- Hernández \& Lopez- Hernández, 2002) e no Sul do Brasil (Balota et al., 1998), o sistema de PD favorece um aumento da biomassa microbiana do solo, comparativamente a solos sob PC.

Além do teor de biomassa microbiana nas diferentes classes de agregados (Quadro 2), também verifica-se como os tratamentos influíram na distribuição do C microbiano nessas classes. Na área sob vegetação nativa, os níveis de CBM nos macroagregados foram significativamentesuperiores aos dos microagregados. J á nas áreas de PD e PC, não houve diferenças significativas na distribuição do CBM entre macro emicroagregados. Nos estudos de Gupta \& Germida (1988) eSingh \& Singh (1995), a distribuição do CBM nos agregados foi semel hante, tanto nas áreas nativas como nas cultivadas, tendo sido os maiores níveis de CBM observados nos macroagregados e os menores, nos microagregados.

No presenteestudo, a ausência de diferenças nos teores de CBM dos macroe microagregados, coletados nas áreas cultivadas, pode estar relacionada com o fato de terem, nessas áreas, os macroagregados apresentado maiores perdas de CBM que os microagregados.

Os teores de carbono prontamente mineralizável foram diferenciados apenas nos macroagregados entre 8,0-2,0 mm, onde a área sob vegetação nativa apresentou teor 1,96 vez superior em relação ao PC (Quadro 2). I sso pode ser atribuído à presença de material rico em compostos orgânicos simples e, portanto, facilmente mineralizáveis, nos macroagregados das áreas nativas (Gupta \& Germida, 1988), estimulando a atividademicrobiana determinada pela liberação de $\mathrm{CO}_{2}$.

Em relação às amostras representando as somas de agregados, não foram observadas diferenças significativas entre as áreas cultivadas ea área sob vegetação nativa, quanto ao carbono prontamente mineralizável (Quadro 2). Esses resultados diferem dos obtidos por Alvarez et al. (1995), Balota et al. (1998), e Mendes et al. (1999b) que observaram mai ores teores de carbono prontamentemineralizável em áreas cultivadas sob PD, comparativamente com áreas sob PC. Guedes (1997) sugeriu que o carbono acumulado no sistema plantio direto estaria no reservatório lábil do solo. Assim, a ausência de diferenças significativas entre o PD e o PC, no presente estudo, pode estar relacionada com o peneiramento úmido utilizado na obtenção dos agregados e do sol o total. É possível que o material orgânico prontamente mineralizável da área sob PD seja mais solúvel em água, perdendo-se durante o processo de peneiramento, o que resultaria na ausência de diferenças entre os dois sistemas. Estudos que comparem os teores de $C$ prontamente mineralizável, antes e depois do fracionamento úmi do, são necessários para confirmar essa hi pótese.

Similarmente ao observado com os teores de CBM, o perfil de distribuição das taxas de carbono mineralizável nas classes de agregados do solo sob vegetação nativa diferiu da distribuição nas áreas cultivadas. Na área sob vegetaçãonativa deCerrado, o teor de carbono mineralizável presente nos macroagregados entre $8,0-2,0 \mathrm{~mm}$ foi significativamente superior ( $1,8 \mathrm{vez}$ ) ao dos microagregados (Quadro 2). J á nas áreas de PD e PC, não houve diferenças significativas nos teores de carbono mineralizável entre macro e microagregados (Quadro 2).

$\mathrm{Na}$ área sob PD, as atividades da $\beta$-glucosidase foram superiores às da área sob vegetação nativa e do PC, sendo que apenas nas amostras somas de agregados, as diferenças não foram estatisticamente significativas (Quadro 2). As atividades dessa enzima no PC não foram diferentes daquelas do Cerrado em todas as classes de agregados aval iadas. Mendes et al . (1999) obtiveram resultados semel hantes, com amostras de solo numa área cultivada durante seis anos sob PD. Conforme ressaltado por Bandick \& Dick (1999), essa maior atividade da $\beta$ glucosi dase pode estar associada não só ao acúmulo, mas também à qualidade dos restos culturais acumulados na superfície do sol o nas áreas sob PD.

A distribuição da atividade da $\beta$-glucosidase nas classes de agregados foi semel hante nas três áreas avaliadas, sendo os maiores val ores observados nos macroagregados e os menores, nos microagregados (Quadro 2). As maiores atividades da $\beta$-glucosidase, observadas nos macroagregados, podem estar relacionadas com a presença de resíduos orgânicos de origem vegetal. Esses resíduos poderiam funcionar como fontes dessa enzima ou como estímulo para sua produção (indução pela presença do substrato).

As maiores atividades da fosfatase ácida e da arilsulfatase nos macroagregados, microagregados e nas somas de agr egados foram observadas na área sob vegetação nativa quando comparadas com as da 
área sob PC (Quadro 2). Em relação ao PD, houve diferença significativa apenas para fosfatase ácida, na amostra soma de agregados, com maiores atividades na área nativa (Quadro 2). A área sob PC apresentou valores de fosfatase ácida e arilsulfatase significativamente menores que os do PD. Doran (1980), nos EUA, e Carneiro (1999), na Região do Cerrado, também observaram que a atividade da fosfatase ácida em áreas sob PD foi superior à de áreas sob PC, em amostras de solo coletadas nas profundidades de 7,5 e $5,0 \mathrm{~cm}$, respectivamente. Em relação à arilsulfatase, Mendes et al. (1999) observaram que a atividade dessa enzima em amostras de solo, na profundidade de 0 a $5 \mathrm{~cm}$, em áreas cultivadas durante seis anos sob PD, foi 1,6 vez superior à de uma área sob PC.

Apesar das maiores concentrações de fósforo no PD (Quadro 1), a mai or atividade da fosfatase ácida, nesse sistema, em relação ao PC, pode ser atribuída ao menor revol vimento do solo, favorecendo, na área de PD, uma maior concentração do adubo fosfatado na camada superficial. Dessa forma, a inibição das fosfatases por esses adubos nãoétão acentuada como no PC, onde eles são misturados ao solo. Conte et al. (2002) destacaram que, apesar das altas concentrações de $P$ nas áreas sob PD, a alta afinidade do P com os colói des organomi nerais do sol o favorece a adsorção dos ânions fosfato, reduzindo seu efeito inibidor sobre a atividade da fosfatase. A maior concentração dos ânions fosfato no PD, nos cinco primeiros centímetros do solo (Quadro 1), também pode ter contribuído para as maiores atividade da arilsulfatase nesse sistema de manejo, visto que os ânions $\mathrm{H}_{2} \mathrm{PO}_{4}{ }^{-}$e $\mathrm{SO}_{4}{ }^{2-}$ competem entre si pelos mesmos sítios de adsorçãonos col óides do solo. Como o ânion $\mathrm{H}_{2} \mathrm{PO}_{4}{ }^{-}$éadsorvido preferencial mentenesses sítios (Tisdale et al., 1993), isso acarretaria uma deficiência de $S$, a qual estimularia a produção e a atividade da arilsulfatase na área sob PD.

As maiores ativi dades da fosfatase earilsul fatase na área sob vegetação nativa e as menores na área de PC refletem a perda de CBM, o efeito inibidor do uso de adubos na atividade enzimática nas áreas cultivadas (Gupta \& Germida, 1988; Mendes, et al., 1999; Conte et al., 2002) e a importância da mineralização do fósforo e enxofre orgânicos, pela ação dessas enzimas, no suprimento desses nutrientes nas áreas nativas.

Além de seus efeitos benéficos sobre as comunidades microbianas (estimulando aumentos de biomassa e atividade microbiana), a matéria orgânica protege e mantém as enzimas do solo em suas formas ativas, pela formação de complexos enzima-compostos húmicos (Dick et al., 1988; Deng \& Tabatabai, 1997). Assim, em adição aos fatores já mencionados, deve-se destacar, no presente estudo, a importância dos maiores teores de matéria orgânica na área sob PD, comparativamente à área sob PC (Quadro 2), na promoção de aumentos de biomassa microbiana e atividade enzimática.
Os sistemas cultivados influenciaram a distribuição dos níveis de atividade da fosfatase ácida e da arilsulfatase nos agregados. Na área sob PD (Quadro 2), as atividades da fosfataseácida e da arilsulfatase nos macroagregados foram, respectivamente, 36 e $67 \%$ superiores às atividades dos microagregados. Na área sob vegetação nativa (Quadro 2), embora as maiores atividades dessas enzimas também tenham sido observadas nos macroagregados, as diferenças entre macro e microagregados não foram significativas. J á na área sob PC, com arado de discos, os níveis de atividade dessas duas enzimas foram semel hantes nos macro e microagregados.

Gupta \& Germida (1988) observaram, em áreas sob vegetação nativa e sob cultivo durante 61 anos, que os perfis de distribuição de fosfatase áci da e de arilsulfatase nos macro e microagregados do solo foram semel hantes nas duas áreas (os macroagregados apresentaram maiores atividades de que os microagregados). A ausência de diferenças nos níveis de atividade dessas enzimas nos macro e microagregados da área sob PC, observados neste estudo, mostra que, além de influir nos níveis de atividade, o sistema de manejo também influencia a distribuição dessas enzimas nas diferentes classes de agregados do solo.

Fatores como acessibilidade, qualidade dos substratos orgânicos e alterações nas comunidades microbianas presentes nas diferentes classes de agregados, nas áreas de PD e PC, podem estar associados às mudanças nos perfis de distribuição, nos macro e microagregados, dos teores de CBM, C mineralizável, fosfatase ácida e arilsulfatase.

Vários trabalhos (Beare et al. 1994; Alvarez et al., 1995; Bal ota et al., 1998; Six et al. 2000) mostram que, alguns anos após o estabel ecimento do PD, as camadas do solo mais próximas à superfície apresentam propriedades químicas, físicas e biológicas diferenciadas. Nas áreas sob PC, onde o revolvimento do solo permite distribuição mais homogênea de adubos e restos culturais no perfil do solo, essa diferenciação não é tão acentuada. Os resultados obtidos neste estudo, com amostras de solo do bioma Cerrado, coletadas na profundidade de 0 a $5 \mathrm{~cm}$, confirmam essas observações. Mais estudos são necessários para verificar os efeitos dos sistemas dePD ePC nas propriedades biológicas dos agregados e de amostras de solo das camadas mais profundas do perfil, bem como para determinar as implicações desses resultados nos processos de agregação e funcionamento biológico dos sol os desse bioma.

\section{CONCLUSÕES}

1. O estabelecimento dos sistemas de cultivo gerou quebra de macroagregados e perdas de 
carbono da biomassa microbiana, em relação a áreas não perturbadas, sob vegetação nativa.

2. A aplicação localizada de adubos, o menor revolvimento do sol o e os mai ores teores de matéria orgânica no PD favoreceram, em relação ao PC, a ocorrência de maiores níveis de fosfatase ácida e arilsulfatase nos agregados e nas amostras que representama soma deagregados. Os microagregados ea soma dos agregados do PD também apresentaram maiores teores de carbono da biomassa microbiana, comparativamente ao PC. As maiores atividades da $\beta$-glucosidase foram observadas nos macro e microagregados do PD.

3. Os sistemas demanejo (PD ePC) influenciaram o perfil de distribuição das propriedades biológicas nos agregados do solo. A atividade das enzimas bglucosidase, fosfataseáci da earilsulfatasefoi maior em macroagregados do PD apesar da distribuição semel hante de carbono da biomassa microbiana nas três classes deagregados avaliadas. No PC, apenas a $\beta$-glucosidase apresentou distribuição diferenciada entre macro e microagregados.

\section{AGRADE CI MENTOS}

Os autores agradecem o auxílio do técnico agrícola Carlos Alberto Cardoso, dos funcionários do laboratório de Microbiologia do Solo: Emílio J . Taveira, Maria das Dores Silva, OdeteJ . dos Santos e Vilderete C. Alves, e dos funcionários do laboratório de Física e Mineral ogia de Solos: J osé R. Ribeiroe Wantuir C. Vieira. Também agradecem o col ega Djalma M.G. Sousa, pelas vali osas discussões.

Trabalho realizado com recursos do PCOPGCNPq (520764/99-4).

\section{LITE RATURA CITADA}

ALBUQUERQUE, J.A.; REINERT, D.J .; FIORIN, J.E.; RUEDELL, J .; PETRENE, C. \& FONTINELLI, F. Rotação de culturas e sistemas de manejo do solo: efeitos sobre a forma da estrutura do solo ao final de sete anos. R. Bras. Ci. Solo, 19:155-119, 1995.

ALVAREZ, R.; DÍAZ, R.A.; BARBERO, N.; SANTANATOGLIA, O.J . \& BLOTTA, L. Soil organic carbon, microbial biomasss and $\mathrm{CO}_{2}-\mathrm{C}$ production from threetillage systems. Soil Till. Res., 33:17-28, 1995.

ANGERS, D.A. Changes in soil aggregation and organic carbon under corn and alfalfa. Soil Sci. Soc. Am. J ., 56:1244-1249, 1992.

BALOTA, E.L.; COLOZZI-FILHO, A.; ANDRADE, D.S. \& HUNGRIA, M. Biomassa microbiana e sua atividade em solos sob diferentes sistemas de preparo e sucessão de culturas. R. Bras. Ci. Solo, 22:641-649, 1998.
BANDICK, A. K. \& DICK, R.P. Field management effects on soil enzyme activities. Soil Biol. Biochem., 31:1471-1479, 1999.

BEARE, M.H.; HENDRIX, P.F. \& COLEMAN, D.C. Water-stable aggregates and organic matter fractions in conventionaland no-tillage soils. Soil Sci. Soc. Am. J ., 58:777-786, 1994.

BUYANOVSKY, G.A.; ASLAM, M. \& WAGNER, G.H. Carbon turnover in soil physical fractions. Soil Sci. Soc. Am. J., 58:1167-1173, 1994.

CARNEIRO, R.G. Dinâmica de parâmetros biológicos associados ao ciclo do fósforo em solo de Cerrado sob diferentes sistemas de manejo. Florianópolis, Universidade Federal de Santa Catarina, 1999. 86p. (Tese de Mestrado)

CARPENEDO, V. \& MIELNICZUK, J. Estado de agregação e qualidade de agregados de Latossol os Roxos, submetidos a diferentes sistemas de manejo. R. Bras. Ci. Solo, 14:99105, 1990.

CARTER, M. Influence of reduced tillage systems on organic matter, microbial biomass, macro-aggregate distribution and structural stability of the surface soil in a humid climate. Soil Till. Res., 1992:361-372, 1992.

CASTRO FILHO, C.; LOURENÇO, A.; GUIMARÃES, M.F. \& FONSECA, I.C.B. Aggregate stability under different soil management systems in a Red Latosol in the sate of Paraná, Brazil. Soil Till. Res., 65:45-51, 2002.

COLEMAN, D.C.; HENDRIX, P.F.; BEARE, M.H.; CROSSLEY, D.A.; HU, S. \& VLIET, P.C.J.V. The impacts of management and biota on nutrient dynamics and soil structure in sub-tropical agroecocystems: I mpacts on detritus food webs. In: PANKHURST, C.E.; DOUBE, B.M.; GUPTA, V.V.S.R. \& GRACE, P.R., eds. Soil biota management in sustainable farming systems. Austrália, CSIRO,1994. p.133-143.

CONTE, E.; ANGHINONI, I. \& RHEINHEIMER, D.S. Fósforo da biomassa microbiana e atividade de fosfatase ácida após aplicação de fosfato em solo no sistema plantio direto. R. Bras. Ci. Solo, 26:925-930, 2002.

DENG, S.P. \& TABATABAI, M.A. Effect of tillage and residue management on enzyme activities in soils: III. Phosphatases and arylsulfatase. Biol. Fertil. Soils, 24:141146, 1997.

DICK, R.P.; RASMUSSEN, P.E. \& KERLE, E.A. Influence of long term residue management on soil enzyme activities in relation to soil chemical properties of a wheat-fallow system. Biol.Fertil. Soils, 6:159-164, 1988.

DORAN, J .W. Soil microbial and biochemical changes associated with reduced tillage. Soil Sci. Soc. Am. J ., 44:765-771, 1980.

DORMAAR, J .F. Chemical properties of soil and water-stable aggregates after sixty-seven years of cropping to spring wheat. Plant Soil, 75:51-61, 1983.

ELLIOTT, E.T. Aggregate structure and carbon, nitrogen and phosphorus in native and cultivated soils. Soil Sci. Soc. Am. J ., 50:627-633, 1986.

EMPRESA BRASILEIRA DE PESQUISA AGROPECUÁRIA EMBRAPA. Serviço Nacional de Levantamento e Conservação do Solo. Manual de análises de solo. 2.ed. Rio de J aneiro, 1997. 212p. 
FRANZLUEBBERS, A.J . \& ARSHAD, M.A. Soil microbial and mineralizable carbon of water-stable aggregates. Soil Sci. Soc. Am. J ., 61:1090-1097, 1997.

FOSTER, R.C. Microorganisms and soil aggregates. In: PANKHURST, C.E.; DOUBE, B.M; GUPTA, V.V.S.R. \& GRACE, P.R., eds. Soil biota: management in sustainable farming systems. East Melbourne, CSIRO, 1994. p.144-155.

GUEDES, H.M. Efeito de diferentes sistemas de manejo na distribuição de classes de agregados e nos teores de C orgânico em um Latossolo Vermelho-Escuro argiloso na região dos Cerrados. Brasília, Universidade de Brasília, 1997. 187p. (Tese de Mestrado)

GUPTA, V.V.S.R. \& GERMIDA, J J . Distribution of microbial biomass and its activity in different soil aggregation size classes as affected by cultivation. Soil Biol. Biochem., 20:777-786, 1988.

HERNÁNDEZ- HERNÁNDEZ, R.M. \& LOPEZ- HERNÁNDEZ, D. Microbial biomass, mineral nitrogen and carbon content in savanna soil aggregates under conventional and notillage. Soil Biol. Biochem., 34:1563-1570, 2002.

J ASTROW, J .D. Changes in soil aggregation associated with tallgrass prairie restoration. Am. J . Bot., 74:1656-1664, 1987.

J ASTROW, J.D. Soil aggregate formation and the accrual of particulate and mineral-associated organic matter. Soil Biol. Biochem., 28:665-676, 1996.

J ENKINSON, D.S. \& POLWSON, D.S. The effect of biocidal treatment on metabolism in soil. V. A method of measuring soil biomass. Soil Biol. Biochem., 8:209-213, 1976.

KEMPER, W.D. \& ROSENEAU, R.C. Aggregate stability and size distribution. In. KLUTE, A., ed. Methods of soil analysis, 1. Physical and mineralogical methods. 2.ed. Madison, America Society of Agronomy, 1986. p.425-442.

MACHADO, J .A.; SOUZA, D.M.P. \& BRUM, A.C.R. Efeitos de anos de cultivo convencional em propriedades físicas do solo. R. Bras. Ci. Solo, 5:187-189, 1981.

MATSUOKA, M. Efeito de diferentes sistemas de cultivo na biomassa e atividade microbiana num Latossolo de MT. Cuiabá, Universidade Federal de Mato Grosso, 2001. 123p. (Tese de Mestrado)

MENDES, I.C.; BANDICK, A.K.; DICK, R.P. \& BOTTOMLEY, P.J. Winter cover crops and the distribution of microbial biomass and activities in soil aggregates. Soil Sci. Soc. Am. J., 63:873-881, 1999a.

MENDES, I.C.; CARNEIRO, R.G.; CARVALHO, A.M.; VIVALDI, L. \& VARGAS, M.A.T. Biomassa C e atividade microbiana em solos de Cerrado sob plantio direto e plantio convencional. Planaltina, EMBRAPA Cerrados, 1999b. 5p. (EMBRAPA Cerrados, Pesquisa em Andamento, 5)

MILLER, M. \& DICK, R.P. Dynamics of soil C and microbial biomass on whole soil aggregates in two cropping systems differing in C-input. Appl. Soil Ecol., 2:253-261, 1995a.

MILLER, M. \& DICK, R.P. Thermal stability and activities of soil enzymes as influenced by crop rotations. Soil Biol. Biochem., 27:1161-1666, 1995b.
MILLER, R.M. \& J ASTROW, J .D. The role of mycorrhizal fungi in soil conservation. In: BETHLENFALVAY, G.J . \& LINDERMAN, R.G., eds. Mycorrhizae in sustainable agriculture. Madison, American Society of Agronomy, 1992. p.29-44. (ASA, Special Publication, 54)

NELSON, D.W. \& SOMMERS, L.E. Total carbon, organic carbon and organic matter. In: PAGE, A.L.; MILLER, R.H. \& KEENEY, D.R., eds. Methods of soil analysis. 2: Chemical and microbiological properties. Madison, America Society of Agronomy, 1982. p.539-580.

OADES, J.M. The role of biology in the formation, stabilization and degradation of soil structure. Geoderma, 56:377-400, 1993.

OLIVEIRA, J .R.A. O impacto desistemas integrados delavouras e pastagens na biomassa-C e na atividade biológica de um Latossolo Vermelho-Escuro de Cerrado. Brasília, Universidade de Brasília, 2000. 115p. (Tese de Mestrado)

OLIVEIRA, J .R.A.; MENDES, I.C. \& VIVALDI, L. Biomassa microbiana de carbono em solos de cerrado sob vegetação nativa e sob cultivo: avaliação dos métodos fumigaçãoincubação e fumigação-extração. R. Bras. Ci. Solo., 25:863871, 2001.

PEREIRA, I.S.; RESCK, D.V.S.; GUEDES, H.M.; SILVA, J .E. \& CASTRO, L.H.R. Efeito de diferentes sistemas de manejo na distribuição de macro e microagregados e no teor de carbono orgânico em Latossol o Vermel ho-Escuro na região dos Cerrados, Brasil. SIMPÓSIO SOBRE O CERRADO, 8.; INTERNATIONAL SYMPOSIUM ON TROPICAL SAVANNAS, 1., Brasília, 1996. Biodiversidade e produção sustentável de alimentos e fibras nos Cerrados. Anais. Planaltina, Empresa Brasileira de Pesquisa Agropecuária, 1996. p.367-371.

RESCK, D.V.S. Dinâmica da matéria orgânica e seus efeitos nas propriedades do solo. In: ENCONTRO DE ROTAÇÃO DE CULTURAS, 2., Campo Mourão., 1993. Ata. Campo Mourão, 1993. p.117-143.

SEECH, A.G. \& BEAUCHAMP, E.G. Denitrification in soil aggregates of different sizes. Soil Sci. Soc. Am., J ., 52:16161621,1988

SINGH, S. \& SINGH, J S. Microbial biomass associated with ware-stable aggregates in forest, savannah and cropland soils of a seasonally dry tropical region, India. Soil Biol. Biochem., 27:1027-1033, 1995.

SIX, J .; PAUSTIAN, K.; ELLIOT, E.T. \& COMBRINK, C. Soil structure and organic matter: distributon of aggregate-size classes and aggregate associated carbon. Soil Sci Soc. Am. J ., 64:681-689, 2000.

TABATABAI, M.A. Soil enzymes. In: WEAVER, R.W.; ANGLE, S. \& BOTTOMLEY, P.J ., eds. Methods of soil analysis: Microbiological and biochemical properties. 2. Madison, Soil Science Society of America, 1994. p.775-833. (SSSA, Book Series, 5)

TISDALE, S.; NELSON, W.L; BEATON, J .D. \& HAVLIN, J .H. Soil fertility and fertilizers. New York, Macmillan Publishing Company, 1993. 634p.

TISDALL, J .M. \& OADES, J .M. Stabilization of soil aggregates by the root systems of ryegrass. Aust. J . Soil Res., 17:429$441,1979$. 